\title{
Inhaled isotonic alkaline versus saline solution and radioaerosol clearance in chronic cough
}

\author{
P. Haidl, B. Schönhofer, K. Siemon, D. Köhler
}

Inhaled isotonic alkaline versus saline solution and radioaerosol clearance in chronic cough. P. Haidl, B. Schönhofer, K. Siemon, D. Köhler. C) ERS Journals Ltd 2000.

ABSTRACT: The aim of the present study was to test the influence of inhaled isotonic Ems salt (brine from the spa of Bad Ems, Germany) compared to isotonic saline on radioaerosol clearance (RC) in patients with chronic cough. Ems salt is an alkaline solution (pH 8.0-9.0) containing largely bicarbonate ions rather than the chloride ions present in isotonic saline (pH 6.4).

RC was assessed with a radioaerosol technique using technetium-99m albumin in supine patients. After a 30-min baseline measurement of RC according to a single blind and randomized design, patients inhaled Ems salt $(n=22,20-77$ yrs) or isotonic saline ( $\mathrm{n}=\mathbf{2 1}, 34-72 \mathrm{yrs}$ ) via a jet nebulizer (Pari Boy) for $10 \mathrm{~min}$ and were scanned for an additional $30 \mathrm{~min}$.

There was no difference between the two groups before intervention in terms of deposition pattern, lung function and baseline RC rate. After inhalation of Ems salt, the $\mathrm{RC}$ rate $(1 / \tau)$ improved significantly from $0.15 \pm 0.14$ (mean $\pm \mathrm{SD})$ to $0.53 \pm 0.70 \mathrm{~L} \cdot \mathrm{h}^{-1}$ $(p<0.005)$; no change was found after isotonic saline $\left(0.13 \pm 0.13\right.$ to $\left.0.08 \pm 0.09 \mathrm{~L} \cdot \mathrm{h}^{-1}, \mathrm{NS}\right)$. Voluntary coughs performed after $60 \mathrm{~min}$ had no effect on the RC rate. However, in the Ems salt group, significantly more patients reported an inhalation induced cough. Compared to the Ems salt patients, who did not cough during and after inhalation, the $\mathrm{RC}$ rate in the cough group was enhanced significantly $(0.10 \pm 0.12$ versus $0.73 \pm 0.83$, $p=0.017)$, this effect being seen more frequently in females $(p=0.003)$.

It is concluded that Ems salt improves radioaerosol clearance significantly in patients with chronic cough. The underlying mechanism, regarding whether induced cough, increased water content in the mucus or enhanced ciliary beat frequency is the leading cause of Ems salt action, remains unclear.

Eur Respir J 2000; 16: 1102-1108.
Krankenhaus Kloster Grafschaft, Zentrum für Pneumologie, Beatmungs- und Schlafmedizin, Schmallenberg, Germany.

Correspondence: P. Haidl

Krankenhaus Kloster Grafschaft

Zentrum für Pneumologie

Beatmungs- und Schlafmedizin

Annostrasse

D-57392 Schmallenberg

Germany

Fax: 4929727912526

Keywords: Alkaline solution

chronic cough

ems salt

radioaerosol clearance

Received: November 231999

Accepted after revision July 252000
Inhalation via a nebulizer is a common therapy in chronic pulmonary diseases. For this purpose, isotonic saline is often used as a carrier [1]. It is already known that hypertonic saline increases mucociliary clearance (MC), whereas this effect has not yet been seen with isotonic saline [2-4].

Ems salt, natural spring water from the spa of $\mathrm{Bad}$ Ems, Germany, is an isotonic alkaline solution with a $\mathrm{pH}$ of 8.0-9.0. Its main difference from isotonic saline is the partial replacement of chloride by bicarbonate ions. Inhalation therapy with Ems salt is common in Germany for diseases of the upper respiratory tract (e.g. chronic rhinosinusitis, postoperative ear, nose and throat therapy) [5] and the treatment of acute and chronic bronchitis. Acceleration of ciliary beat frequency (CBF) in isolated cultured human ciliated cells observed via inverted phasecontrast microscope as well as reduction of sputum viscoelasticity in patients with cystic fibrosis and chronic bronchitis has been reported in vitro for Ems salt $[6,7]$. Both of these mechanisms would influence MC, which is determined by many factors: the quantity, components and viscosity of sputum, ciliary function and epithelial integrity [8]. An important role is played by the interaction between mucus viscosity, periciliary fluid and the ciliary apparatus [9]. Cough can indicate dysfunction of these components, especially in chronic bronchitis, and may serve as a back-up system [10]. In this disease, hypertrophy of submucosal glands, an increased number of goblet cells and a reduction in the number of ciliated cells have been described histologically [8]; these could all account for a reduction in MC [8, 10].

Were Ems salt to reduce sputum viscoelasticity and increase $\mathrm{CBF}$ in vivo, the impaired $\mathrm{MC}$ in diseases involving chronic cough might be improved. Therefore, a study was performed examining the effects of inhalation of Ems salt compared to isotonic saline on radioaerosol clearance (RC), based on MC and cough clearance, in patients with chronic cough.

\section{Methods}

\section{Patients}

The present study was conducted between February 1996 and April 1997. Forty-three patients aged 20-77 yrs were investigated. Informed consent was obtained prior to enrolment. MC was routinely assessed to quantify the 
impairment (e.g. in patients with a chronic cough $(\mathrm{n}=36)$, dyskinetic cilia syndrome $(\mathrm{n}=1)$ and bronchiectasis $(\mathrm{n}=6))$. Chronic cough was defined as a cough of $>3$ months duration in the presence of a normal chest radiograph or as a cough with a pathological chest radiograph without any change within the last 3 months. In the study design, the patients served as their own controls. Thus theophylline and oral corticosteroid medication were not discontinued. In the morning before the investigation, the patients were not allowed to smoke, use nebulizer therapy or take mucoactive drugs (e.g. acetylcysteine and ambroxol). In a randomized single-blind manner, 22 patients inhaled Ems salt and 21 isotonic saline. Anthropometric and baseline lung function data as well as the drug use of the patients are detailed in table 1 .

\section{Study design}

In a preliminary study (unpublished data, $n=20$ ), it was possible to demonstrate that the inhalation of Ems salt did not trigger bronchial obstruction in patients with asthma even when severe hyperreactivity was present. After inhalation of the radioaerosol, patients were immediately placed in the supine position under a gamma camera for a total period of $70 \mathrm{~min}$. They were advised not to cough. Isotonic saline or Ems salt $(\sim 3.0 \mathrm{~mL})$ was inhaled for a period of 10 min using a tidal breathing pattern by means of a 20-cm long flexible tube from a jet nebulizer (Pari Boy compressor, Pari LL nebulizer, (Pari, Starnberg, Germany) mass median aerodynamic diameter (MMAD) $4.1 \mu \mathrm{m}$ (measured with the Malvern mastersizer (Malvern Instruments Ltd., Worchestershire, UK) at a flow rate of $20 \mathrm{~L} \cdot \mathrm{min}^{-1}$, temperature of $23^{\circ} \mathrm{C}$ and relative humidity of $50 \%) 30$ min after starting to measure radioactivity [11]. Separate measurement showed no influence of the tube on particle size. All patients were already familiar with the nebulizer therapy. A 30-min postintervention measurement period followed. The patients performed five voluntary cough manoeuvres to assess cough clearance 10 min before the end. On completion, a brief questionnaire dealing with coughs and side-effects was administered (table 2).

Table 1. - Diagnosis, biometric and lung function data, and comedication

\begin{tabular}{lccc}
\hline & Isotonic saline & Ems salt & p-value \\
\hline Subjects $\mathrm{n}$ & 21 & 22 & \\
Males n & 9 & 10 & \\
Chronic cough n & 18 & 18 & \\
Bronchiectasis $\mathrm{n}$ & 3 & 4 & \\
Age yrs & $54.6 \pm 1.2$ & $53.8 \pm 16.8$ & $\mathrm{NS}$ \\
Height cm & $168.2 \pm 8.2$ & $170.1 \pm 8.4$ & $\mathrm{NS}$ \\
Weight kg & $73.6 \pm 17.4$ & $79.4 \pm 21.2$ & $\mathrm{NS}$ \\
Rtot $\mathrm{kPa} \cdot \mathrm{L} \cdot \mathrm{s}-1$ & $0.40 \pm 0.22$ & $0.38 \pm 0.22$ & $\mathrm{NS}$ \\
FEV $1 \%$ pred & $83.0 \pm 23.7$ & $86.8 \pm 18.0$ & $\mathrm{NS}$ \\
IVC \% pred & $89.8 \pm 21.8$ & $92.6 \pm 16.6$ & $\mathrm{NS}$ \\
Nonsmoker $\mathrm{n}$ & 13 & 14 & $\mathrm{NS}$ \\
Theophylline $\mathrm{n}$ & 6 & 7 & $\mathrm{NS}$ \\
Oral steroids $\mathrm{n}$ & 2 & 3 & $\mathrm{NS}$ \\
\hline
\end{tabular}

Data are presented as mean \pm SD. Rtot: total resistance; FEV1: forced expiratory volume in one second; IVC: inspiratory vital capacity; \% pred: percentage of the predicted value; NS: nonsignificant.
Table 2. - Questionnaire results

\begin{tabular}{lrrrrrr}
\hline & \multicolumn{2}{c}{ Ems salt } & & \multicolumn{2}{c}{ Isotonic saline } \\
\cline { 2 - 3 } \cline { 5 - 6 } & Yes & No & & Yes & No \\
\hline Questionnaires completed $\mathrm{n}$ & \multicolumn{2}{c}{$21 / 22$} & & \multicolumn{2}{c}{$13 / 21$} \\
Did inhalation provoke cough? & 14 & 7 & & 4 & 9 \\
Was cough productive? & 7 & 7 & & 0 & 4 \\
Do you have side-effects? & 0 & 21 & & 0 & 13 \\
\hline
\end{tabular}

\section{Intervention solutions}

The isotonic saline $(0.9 \%)$ comprised $152 \mathrm{mM} \mathrm{Na}^{+}, 154$ $\mathrm{mM} \mathrm{C} 1^{-}$and no $\mathrm{HCO}_{3}{ }^{-}$(pH 6.4). The Ems salt (1.1\%, isotonic) comprised $154 \mathrm{mM} \mathrm{Na}^{+}, 63 \mathrm{mM} \mathrm{Cl}^{-}$, and $91 \mathrm{mM}$ $\mathrm{HCO}_{3}{ }^{-}(\mathrm{pH}$ 8.0-9.0). The nebulizer was charged with 5 $\mathrm{mL}$ of solution and the amount remaining in the delivery system was measured.

The effect of the test solutions on the frequency of cough in 12 healthy nonsmoking volunteers $(22-51$ yrs, six males) was also studied. In a randomized blind manner with cross-over design, the subjects inhaled Ems salt and isotonic saline over $10 \mathrm{~min}$ with the same nebulizer as used in the study. During inhalation and the following 30-min rest, both cough frequency and the feeling of wanting to clear the throat (indicating enhanced movement of mucus towards the glottis) were assessed.

\section{Measurement of mucociliary clearance}

First, a transmission scan of the lungs was obtained using a technetium-99m flood source. Then the patients inhaled a polydisperse radioaerosol containing $1.9 \mathrm{GBq}$ ${ }^{99 \mathrm{~m}} \mathrm{Tc}$ albumin diluted in saline (MMAD $1.4 \mu \mathrm{m}$ ) and delivered by a device constructed in-house to ensure central deposition [12]. By means of a bag in box system and a small balloon, the inspiratory volume was limited to $100 \mathrm{~mL}$ (fig. 1). Thus the patient could only ventilate the dead space. This manoeuvre enhanced the central deposition of the aerosol. Ten breaths were followed by a short break; this procedure was performed until the bag was empty.

Afterwards the patients were placed in the supine position under a gamma camera (Dyna Camera 4/15, Picker, Cleveland, OH, USA) and scanned with continuous 2-min images for $70 \mathrm{~min}$.

\section{Data analysis}

The transmission gamma camera scan (fig. 2a) was used to define the outline of the lung. Regions of interest (ROIs) demarcating the central and peripheral parts of the lung were created (fig. 2b) as previously described [13]. $\mathrm{MC}$ was proportional to the amount of radioactivity in the central ROI. The initial deposition of the radioaerosol was determined using the penetration index (PI, ratio of amount of radioactivity per pixel in the peripheral to the central ROI).

All measurements of radioactivity were corrected for radioactive decay. The decrease in activity $(\mathrm{RC})$ is approximately described by the exponential function $\mathrm{I} t=\mathrm{I} 0 \mathrm{e}^{-\mathrm{t} / \tau}$, where $t=$ time and $\tau$ the time constant. RC is characterized by $1 / \tau$. 
a)

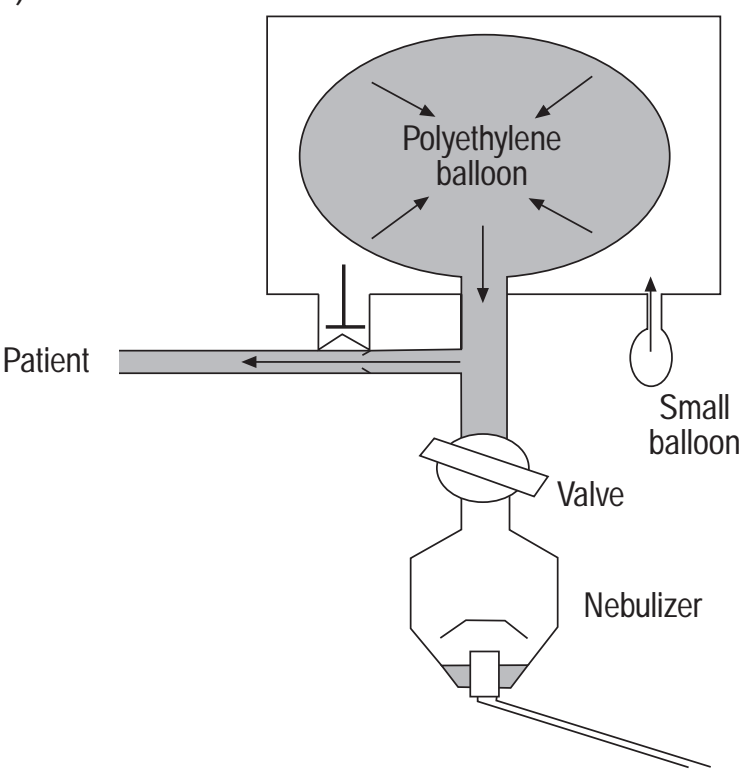

b)

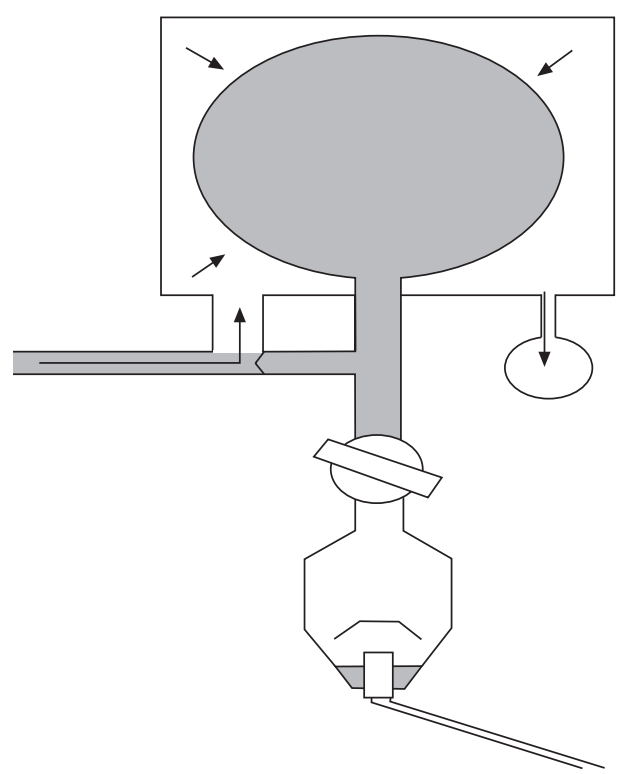

Fig. 1. - Inhalation device for the technetium- $99 \mathrm{~m}$ albumin aerosol ensuring a central deposition pattern. First, the antistatic polyethylene balloon (4 L) inside the box is filled with aerosol from the nebulizer and then the valve was closed. a) Inhalation is limited by means of a small ( $\sim 100 \mathrm{~mL})$ balloon. b) During exhalation, the patient breathes into the box and fills the small balloon. The inhalation manoeuvres are performed with pauses to avoid dyspnoea until the balloon is empty.

Lung function data were measured using a body plethysmograph (Masterlab; Jäger, Würzburg, Germany) using the Masterlab normal values [14].

\section{Statistical analysis}

The Mann-Whitney U-test was used to compare RC rates and patient data. A p-value of $<0.05$ was considered significant. The Wilcoxon matched-pairs test was em-

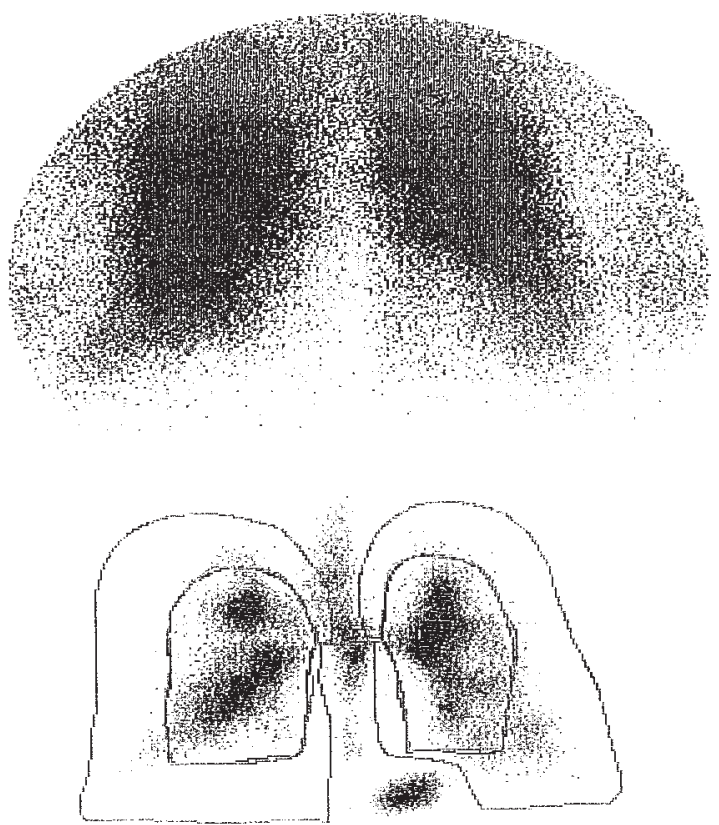

Fig. 2. - a) Transmission gamma camera scans of the lung outline; and b) deposition pattern after inhalation of radioaerosol. The central and peripheral regions of interest are indicated. ployed to compare $\mathrm{RC}$ rates before and after intervention [15]. Data are presented as mean $\pm \mathrm{SD}$ if not otherwise specified.

\section{Results}

Anthropometric and lung function data, smoking habits and comedication were not significantly different between the two groups (table 1). There was no significant difference in initial radioaerosol deposition, as described by the PI, and baseline $\mathrm{RC}$ rate $(0-30 \mathrm{~min})$ (table 3$)$. Both groups inhaled approximately the same amount of isotonic saline or Ems salt (table 3). No correlation was found between cigarette smoking and baseline $\mathrm{RC}$ rate $\left(0.14 \pm 0.10 \mathrm{~L} \cdot \mathrm{h}^{-1}\right.$ versus $0.16 \pm 0.16 \mathrm{~L} \cdot \mathrm{h}^{-1}$ for smokers and exsmokers versus nonsmokers $\mathrm{p}=0.94$ ).

The mean time/activity curves are depicted in figure 3 . $\mathrm{RC}$ rate $(1 / \tau)$ did not increase after inhalation of isotonic saline but was significantly enhanced after inhalation of Ems salts (fig. 4, table 3). This effect was already to be seen during the intervention (fig. 3). Ten patients in the

Table 3. - Deposition pattern and radioactive clearance rates $(1 /$ time constant $(\tau))$

\begin{tabular}{lccc}
\hline & Isotonic saline & Ems salt & p-value \\
\hline Subjects $\mathrm{n}$ & 21 & 22 & \\
PI & $0.45 \pm 0.10$ & $0.48 \pm 0.10$ & NS \\
Baseline $1 / \tau \mathrm{L} \cdot \mathrm{h}^{-1}$ & $0.13 \pm 0.13$ & $0.15 \pm 0.14$ & $\mathrm{NS}$ \\
Postintervention $1 / \tau$ & $0.08 \pm 0.09$ & $0.53 \pm 0.70$ & $<0.005$ \\
$\mathrm{~L} \cdot \mathrm{h}^{-1}$ & & & \\
Nebulized solution $\mathrm{mL}$ & $2.8 \pm 0.5$ & $3.0 \pm 0.8$ & $\mathrm{NS}$ \\
\hline
\end{tabular}

Data are presented as mean \pm SD. PI: penetration index (ratio of amount of radioactivity pixel in the peripheral to the central region of interest). 


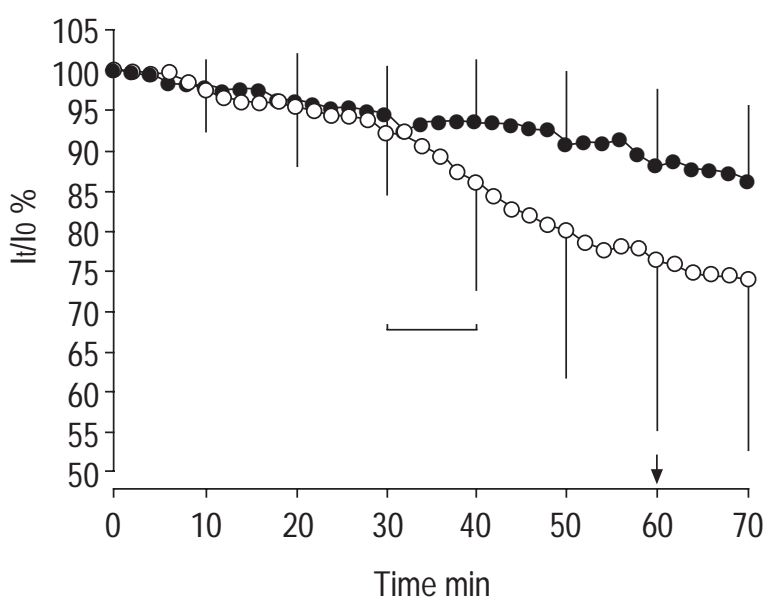

Fig. 3. - Time course of decline in activity in the central region of the lung in the isotonic saline $(O, n=21)$ and Ems salt $(O, n=22)$ groups. The period during which the isotonic saline or Ems salt was inhaled is indicated by the horizontal bar. The vertical arrow indicates a voluntary vigorous cough. I0: initial impulse (radioactive counts); It: impulse at time $t . \mathrm{p}<0.005$.

ES group showed acceleration of $\mathrm{RC}$ rate in the postintervention period of $>20 \%$. This subgroup was defined as responding to Ems salt treatment. No responders were found in the isotonic saline group (fig. 4). The biometric and lung function data, deposition pattern and smoking history of the responders was not different from that of the nonresponders in the Ems salt group (table 4). In the Ems salt group, there was a tendency towards a better forced expiratory volume in one second (FEV1), but no correlation $(\mathrm{r}=0.07)$ was seen between the magnitude of the FEV1 and the increase in RC due to the Ems salt. The Ems salt patients reported more fequent stimulation of cough $(67 \%$ versus $31 \%$ in isotonic saline patients; $\mathrm{p}<0.05)$ in the questionnaire. Nine of the 10 responders reported cough (productive in $44 \%$ ) and one patient failed to answer their questionnaire. In the Ems salt group, the $\mathrm{RC}$ rate of the coughing subjects compared to the patients without cough was enhanced significantly, the proportion of females being higher (table 5). Four of the seven females were nonsmokers. None of the isotonic saline
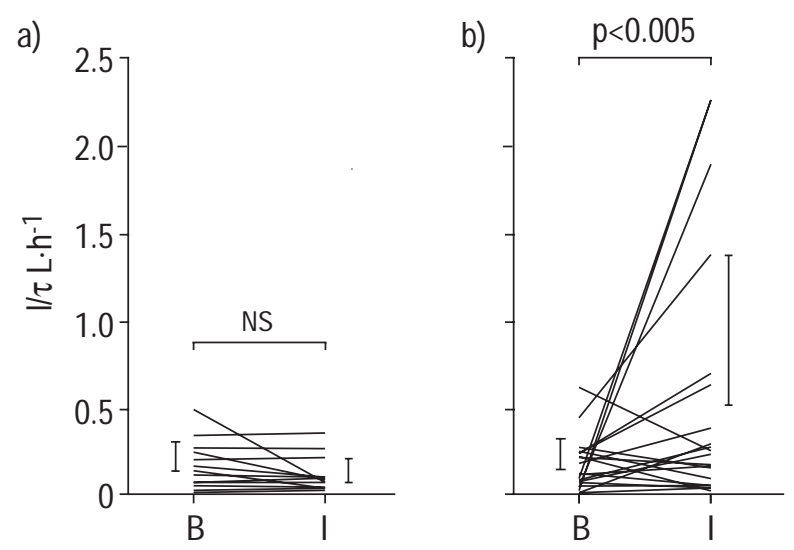

Fig. 4 - Comparison of the baseline radioactive clearance rate $(1 /$ time constant $(\tau))(0-30 \mathrm{~min}$; B) with that following inhalation $(30-70 \mathrm{~min}$; I) of: a) isotonic saline; and b) Ems salt. Vertical bars represent mean \pm SD. NS: nonsignificant.
Table 4. - Biometric and lung function data, deposition pattern and radioactive clearance rate: (1/time constant $(\tau))$ among responders and nonresponders in the Ems salt group

\begin{tabular}{lccc}
\hline & Nonresponders & Responders & p-value \\
\hline Subjects n & 12 & 10 & \\
Males n & 7 & 3 & \\
Bronchiectasis n & 3 & 1 & \\
Age yrs & $54.4 \pm 18.9$ & $53.1 \pm 14.9$ & NS \\
Height cm & $168.6 \pm 8.8$ & $171.8 \pm 8.0$ & NS \\
Weight kg & $70.6 \pm 15.0$ & $89.0 \pm 23.5$ & NS \\
Rtot $\mathrm{kPa} \cdot \mathrm{L} \cdot \mathrm{s}^{-1}$ & $0.36 \pm 0.17$ & $0.41 \pm 0.26$ & $\mathrm{NS}$ \\
FEV1 \% pred & $84.3 \pm 19.9$ & $89.6 \pm 16.2$ & $\mathrm{NS}$ \\
IVC \% pred & $93.1 \pm 19.6$ & $92.0 \pm 13.7$ & $\mathrm{NS}$ \\
Penetration index & $0.48 \pm 0.09$ & $0.49 \pm 0.10$ & $\mathrm{NS}$ \\
Baseline $1 / \tau \mathrm{L} \cdot \mathrm{h}^{-1}$ & $0.15 \pm 0.15$ & $0.16 \pm 0.13$ & $\mathrm{NS}$ \\
Postintervention $^{1} \tau \mathrm{L} \cdot \mathrm{h}^{-1}$ & $0.11 \pm 0.1$ & $1.01 \pm 0.83$ & $<0.005$ \\
\hline
\end{tabular}

Data are presented as mean \pm SD. Rtot: total resistance; FEV1: forced expiratory volume in one second; IVC: inspiratory vital capacity; \% pred: percentage of the predicted value; NS: nonsignificant.

patients considered their cough productive. No significant changes in clearance rate were noted following the five voluntary coughs after $60 \mathrm{~min}$ in either group (fig. 3).

Finally, in healthy subjects, it was found that Ems salt and isotonic saline did not differ concerning cough provocation (table 6).

\section{Discussion}

The major finding of the present study was significantly enhanced RC after inhalation of Ems salt. No effect was found following inhalation of isotonic saline.

What are the underlying mechanisms accounting for the improvement in RC in the Ems salt group? The observed effect may be caused by an improvement in $\mathrm{MC}$, the stimulation of cough or both. MC depends upon a successful relationship between three components: mucus, cilia and periciliary fluid [8].

In vitro investigations have shown a reduction in sputum viscoelasticity by $1.1 \%$ Ems salt [7]. The sputum was

Table 5. - Biometric and lung function data, deposition pattern and radioactive clearance rate $(1 /$ time constant $(\tau))$ among patients who reported a cough versus no cough in the Ems salt group

\begin{tabular}{lccc}
\hline & Cough & No cough & p-value \\
\hline Subjects n & 14 & 7 & \\
Females n & 11 & 1 & $<0.05$ \\
Age yrs & $53.2 \pm 15.9$ & $54.1 \pm 20.8$ & NS \\
Height cm & $168.7 \pm 9.0$ & $172.9 \pm 7.6$ & NS \\
Weight kg & $82.5 \pm 25.2$ & $72.8 \pm 11.5$ & NS \\
FEV1 \% pred & $87.9 \pm 21.4$ & $84.2 \pm 12.2$ & NS \\
Penetration index & $0.47 \pm 0.10$ & $0.50 \pm 0.10$ & NS \\
Baseline $1 / \tau \mathrm{L}^{-1}$ & $0.15 \pm 0.12$ & $0.15 \pm 0.12$ & NS \\
Postintervention $^{-1} \mathrm{~L}^{-1}$ & $0.73 \pm 0.83$ & $0.10 \pm 0.12$ & $<0.005$ \\
& & &
\end{tabular}

Data are presented as mean $\pm \mathrm{SD}$. FEV1: forced expiratory volume in one second; \% pred: percentage of the predicted value; Ns: nonsignificant. 
Table 6. - Frequency of cough and the feeling of wanting to clear the throat during inhalation (0-10 min; I) and the following 30-min (11-40 min; $R$ ) rest

\begin{tabular}{|c|c|c|c|c|c|c|c|c|c|c|c|c|}
\hline \multirow{3}{*}{ Subject No } & \multicolumn{6}{|c|}{ Ems salt } & \multicolumn{6}{|c|}{ Isotonic saline } \\
\hline & \multicolumn{3}{|c|}{ Cough } & \multicolumn{3}{|c|}{ Clearing the throat } & \multicolumn{3}{|c|}{ Cough } & \multicolumn{3}{|c|}{ Clearing the throat } \\
\hline & I & $\mathrm{R}$ & $\Sigma$ & I & $\mathrm{R}$ & $\Sigma$ & I & $\mathrm{R}$ & $\Sigma$ & I & $\mathrm{R}$ & $\Sigma$ \\
\hline 1 & 0 & 0 & 0 & 1 & 0 & 1 & 0 & 0 & 0 & 0 & 0 & 0 \\
\hline 2 & 0 & 0 & 0 & 0 & 0 & 0 & 0 & 0 & 0 & 0 & 0 & 0 \\
\hline 3 & 0 & 0 & 0 & 0 & 0 & 0 & 0 & 0 & 0 & 0 & 0 & 0 \\
\hline 4 & 0 & 0 & 0 & 0 & 0 & 0 & 0 & 0 & 0 & 0 & 0 & 0 \\
\hline 5 & 1 & 1 & 2 & 0 & 2 & 2 & 0 & 0 & 0 & 0 & 0 & 0 \\
\hline 6 & 0 & 0 & 0 & 0 & 0 & 0 & 0 & 0 & 0 & 0 & 0 & 0 \\
\hline 7 & 0 & 0 & 0 & 0 & 1 & 1 & 0 & 0 & 0 & 0 & 0 & 0 \\
\hline 8 & 0 & 0 & 0 & 0 & 1 & 1 & 0 & 0 & 0 & 0 & 0 & 0 \\
\hline 9 & 0 & 0 & 0 & 0 & 0 & 0 & 0 & 7 & 7 & 0 & 1 & 1 \\
\hline 10 & 0 & 0 & 0 & 0 & 0 & 0 & 0 & 0 & 0 & 0 & 0 & 0 \\
\hline 11 & 0 & 0 & 0 & 0 & 1 & 1 & 0 & 2 & 2 & 0 & 3 & 3 \\
\hline 12 & 4 & 3 & 7 & 0 & 3 & 3 & 0 & 0 & 0 & 0 & 0 & 0 \\
\hline Mean & 0.4 & 0.3 & 0.8 & 0.1 & 0.7 & 0.8 & 0 & 0.8 & 0.8 & 0 & 0.3 & 0.3 \\
\hline $\mathrm{SD}$ & 1.2 & 0.9 & 2.1 & 0.3 & 1.0 & 1.3 & 0 & 2.1 & 2.1 & 0 & 0.9 & 0.9 \\
\hline
\end{tabular}

$\Sigma$ : sum. The means did not differ significantly between the two groups (Wilcoxon matched-pairs test).

obtained from patients with chronic obstructive lung diseases. Four per cent Ems salt produced an increase in the mucus clearance index as well as the cough clearance index compared to isotonic saline. Mucus is a complex non-Newtonian viscoelastic gel, containing 9095\% water and $1-2 \%$ mucins [8]. Different intra- and intermolecular bonds are responsible for its netlike structure. An alkaline solution might break the bonds and change the mucus configuration, leading to improved rheological properties. In just this way, the $\mathrm{pH}$ of the airway liquid affects mucus hydration [16]. CHENG et al. [17] reported a decrease in sputum viscosity and the dry/ wet ratio of sputum after inhalation of an alkaline solution in patients with bronchiectasis. Thus improvement in mucus rheology might have contributed to the observed effect of Ems salt.

DiRnaGl et al. [18] investigated the influence of $\mathrm{pH}$ on $\mathrm{CBF}$ in vitro (rat tracheal rings) and found an increase in CBF after exposure to mild alkaline solution ( $\mathrm{pH}$ 9.3). In contrast, CLARY-MEINESZ et al. [19] recently studied the influence of external $\mathrm{pH}$ on $\mathrm{CBF}$ in vitro. The measurements were made in human lung tissue resected because of tumours. In the bronchi, the CBF was not significantly modified when $\mathrm{pH}$ ranged 7.5-10.5; below $\mathrm{pH} 7.0$, the $\mathrm{CBF}$ decreased. This confirmed in vitro results reported by VAN DE DONK et al. [20]. Using a photoelectric registration device, vAN DE DONK et al. [20] found no influence of $\mathrm{pH}$ in the range 7-10 on the CBF of rat trachea. In conclusion, it is unlikely that the alkaline $\mathrm{pH}$ of Ems salt is an essential cause of the improvement in RC.

However, two authors have reported an increase in CBF in humans caused by Ems salt. DiRNAGL et al. [18] used the saccharin test to assess the MC of the nose. Wolf et al. [6] observed the CBF of isolated cultured human ciliated cells through an inverted phase-contrast microscope. Under physiological conditions, Ems salt had a positive but not significant influence on CBF compared to isotonic saline. After damage of the cultivated cells by $1 \%$ propanolol, Ems salt induced significant acceleration of regeneration of the cells compared to isotonic saline. Thus it may be speculated that an unknown mechanism independent of $\mathrm{pH}$ stimulates $\mathrm{CBF}$ and causes enhancement of RC. The third factor which influences $\mathrm{MC}$ is the composition of the periciliary fluid. In Ems salt, compared to isotonic saline, the ionic composition is altered, $\mathrm{Cl}^{-}$being partially replaced by $\mathrm{HCO}_{3}^{-}$, but the overall strength being unchanged. However, reducing the $\mathrm{Cl}^{-}$ concentration in the extemal medium may stimulate transepithelial $\mathrm{Cl}^{-}$transport in compensation, given the fact that the epithelium is less permeable to $\mathrm{HCO}_{3}{ }^{-}$than to $\mathrm{Cl}^{-}$[21], thereby promoting hydration of the airway surface fluid and improving its clearability.

The measurement of MC is markedly influenced by the deposition pattem of the radioactive aerosol [10, 13]. Owing to a lower percentage of ciliated cells, shorter cilia and slower beat frequency, MC is reduced in peripheral airways $[8,10]$. Higher peripheral deposition in one group would have resulted in underestimation of the effects of the intervention. However, there was no difference in the initial deposition pattern, characterized by PI.

The absolute degree of baseline MC may influence the results [8]. The greater the impairment before intervention, the greater the possibility of enhancing MC. In the present study, the baseline RC rate showed no significant difference between the two groups (table 3). A mean $1 / \tau$ of $0.13-0.15$ indicates slightly reduced MC. Previous data have shown values of $>0.25 \mathrm{~L} \cdot \mathrm{h}^{-1}$ in healthy subjects [10].

Besides MC, cough plays an important role in bronchial clearance. BENNETT et al. [22] studied the effectiveness of cough in clearing mucus in 12 nonsmoking healthy subjects. Acceleration of MC by voluntary coughs was found at 1 as well as $2 \mathrm{~h}$ after the beginning of measurement. Cough seemed to stimulate MC directly. Patients in the Ems salt group, especially responders, reported more frequent stimulation of cough. Comparison of the RC rates before and after intervention (table 5) revealed significant improvement, particularly in subjects with cough. However, in five of 14 patients, RC was not enhanced by cough. In addition, there was no change in $\mathrm{RC}$ rate after voluntary cough. The tracer had probably 
already been cleared at that juncture. The improved MC before voluntary coughs causes a reduced mucus layer, which may be responsible for the limited effect of cough. In further studies, it might be better to perform the voluntary coughs earlier in the measurement period.

Analysis of the individual RC curves showed a homogenous decrease in the group with accelerated RC. If cough were the main mechanism, steps according to coughs would be expected in the course of the curve. Further, the enhancement of RC starts soon after the Ems salt inhalation (fig. 3), supporting the fluidification hypothesis. The present results suggest that an increased number or an enhanced effectiveness of coughs might have accounted for the improved RC rate. However, it was found that inhalation of neither Ems salt nor isotonic saline induced a remarkable number of coughs in healthy subjects (table 6). Based on these results, Ems salt seems not to be a nonspecific cough inducer.

There are very few data available to explain the observed promoting effect of Ems salt on MC or cough clearance. Analysis of the data of responders (table 4) and patients with cough (table 5) in the Ems salt group revealed no indications as to the possible cause nor predictive factors as to which group of patients will show beneficial effects. Interestingly, in the group of patients with cough, the number of females was obviously higher than that in the group without cough (table 5). Four of the seven females reporting cough were nonsmokers.

One limitation of the present study is that the total number of spontaneous coughs in the two groups were not measured. Subjective cough assessment is a scientifically weak measurement. Counting their own coughs was not regarded as being precise. Thus a questionnaire was chosen in combination with voluntary coughs at the end of the measurement period. For future studies, a portable cough recorder has recently been developed and validated to deal with the problem [23].

Another limitation is the characterization of the study population, which is heterogeneous. Owing to the concerns of the ethics board concerning the use of radiolabelled particles, only patients in whom the measurement of $\mathrm{MC}$ was part of their routine diagnostic work-up during a hospital stay were investigated. Therefore, the main indications were clarification of the cause chronic cough, determination of the degree of impairment of $\mathrm{MC}$ in patients with bronchiectases and detection of immotile cilia syndrome. The present results may now permit measurement of the effect of Ems salt on bronchial clearance in a better-defined group, e.g. patients with chronic bronchitis.

The question has been raised as to why isotonic saline was chosen as the placebo in the control group. Although hypertonic saline has an increasing effect on MC [2-4], it may cause airway narrowing in patients with additional bronchial hyperresponsiveness and thus is rarely used in clinical practice. In addition, this would have involved investigating an isotonic versus a hypertonic solution, thus introducing another variable. Therefore, it was preferable that the two isotonic solutions were compared.

Ems salt may be a potentially useful treatment in patients with chronic bronchitis, independent of whether the effect is achieved by enhancement of cough clearance or MC. Based on the present results, it may be speculated that Ems salt as a basic solution in nebulizer therapy is superior to isotonic saline. Improved bronchial clearance leads to a shorter exposure to inhalative pollutants and faster clearance of endogenous infectious material. Conversely, it is not known how long the effect persists and whether it is beneficial in the course of chronic bronchitis.

In summary, isotonic Ems salt, an alkaline solution containing bicarbonate ions, increased radioaerosol clearance significantly compared to isotonic saline. In the Ems salt group, significantly more patients reported cough. This subgroup, especially, showed improved radioaerosol clearance, this being seen more frequently in females. The authors favour the hypothesis that the replacement of chloride by bicarbonate ions initially results in enhanced fluidification of airway surface liquid followed by cough provocation with greater effectiveness of the cough. In addition, improvement in mucus viscosity as well as $\mathrm{pH}-$ independent stimulation of ciliary beat frequency could be a factor.

Acknowledgements. The authors would like to thank M. Knowles, University of North Carolina, sincerely for reviewing this manuscript and offering suggestions for further revision.

\section{References}

1. Salathe M, O'Riordan TG, Wanner A. Treatment of mucociliary dysfunction. Chest 1996; 110: 1048-1057.

2. Pavia D, Thomson ML, Clarke SW. Enhanced clearance of secretions from the human lung after administration of hypertonic saline aerosol. Am Rev Respir Dis 1978; 117: 199-203.

3. Robinson M, Hemming AL, Regnis JA, et al. Effect of increasing doses of hypertonic saline on mucociliary clearance in patients with cystic fibrosis. Thorax 1997; 52: 900-903.

4. Daviskas E, Anderson SD, Gonda I, et al. Inhalation of hypertonic saline aerosol enhances mucociliary clearance in asthmatic and healthy subjects. Eur Respir $J$ 1996; 9: 725-732.

5. Michel O, Charon J. Postoperative Inhalationsbehandlung nach Nasennebenhöhleneingriffen. HNO 1991; 39: 433438.

6. Wolf G, Koidl B, Pelzmann B. Zur Regeneration des Zilienschlages humaner Flimmerzellen. Laryngorhinootologie 1991; 70: 552-555.

7. App EM, Danzl G, King M, Heyder J. In vitro sputum rheology changes in cystic fibrosis, chronic bronchitis and asthma lung diseases following the application of different salt solutions. Am J Respir Crit Care Med 1996; 153: A824.

8. Wanner A, Salathe M, O'Riordan TG. Mucociliary clearance in the airways. Am J Respir Crit Care Med 1996; 154: 1868-1902.

9. Sleigh MA, Blake JR, Liron N. The propulsion of mucus by cilia. Am Rev Respir Dis 1988; 137: 726-741.

10. Köhler D, Vastag E. Bronchiale clearance. Pneumologie 1991; 45: 314-332.

11. Dennis JH. Drug nebulizer design and performance: breath enhanced jet $v s$. constant output jet $v s$. ultrasonic. $J$ Aerosol Med 1995; 8: 277-280.

12. Siemon K, Rolle M, Becker-Breitbarth A, Haidl P, Köhler D. A new device for central deposition of aerosols with a wide range of particle size in the bronchial tree. J Aerosol Med 1996; 9: 541.

13. Agnew JE, Pavia D, Clarke SW. Airways penetration of 
inhaled radioaerosol: an index to small airways function? Eur J Respir Dis 1981; 62: 239-255.

14. Quanjer PH, Dalhuijsen A, Van Zomeren BC. Summary equations of reference values. Bull Eur Physiopathol Respir 1983; 19 (Suppl. 5): 45-51.

15. Sachs L. Angewandte Statistik. Berlin, Springer, 1992.

16. Verdugo P. Hydration kinetics of exocytosed mucins in cultured secretory cells of the rabbit trachea: a new model. Ciba Found Symp 1984; 109: 212-225.

17. Cheng HF, Lin HC, Yu CT, Kuo HP. Effect of aerosolized alkaline solution on patients with bronchiectasis with sputum hypersecretion. Eur Respir J 1995; 8: 390s.

18. Dimagl K, Guillerm R, Hee J, Badre R, Schnelle KW. Untersuchungen über den Einfluß von Soleverdünnungen unterschiedlichen $\mathrm{pH}$-Wertes auf die ziliäre Transportfunktion. Z Angew Bader u Klimaheilk 1979; 26: 5-14.

19. Clary-Meinesz C, Mouroux J, Cosson J, Huitorel P,
Blaive B. Influence of external $\mathrm{pH}$ on ciliary beat frequency in human bronchi and bronchioles. Eur Respir $J$ 1998; 11: 330-333.

20. van de Donk HJM, Zuidema J, Merkus HM. The influence of the $\mathrm{pH}$ and osmotic pressure upon tracheal ciliary beat frequency as determined with a new photoelectric registration device. Rhinology 1980; 18: 93-104.

21. Trout L, Gatzy JT, Ballard ST. Acetylcholine-induced liquid secretion by bronchial epithelium: role of $\mathrm{Cl}^{-}$ and $\mathrm{HCO}_{3}{ }^{-}$transport. Am J Physiol 1998; 275: L1095L1099.

22. Bennett WD, Foster WM, Chapman WF. Cough-enhanced mucus clearance in the normal lung. J Appl Physiol 1990; 69: 1670-1675.

23. Köhler D, Klauke M, Schönhofer B. Ein portabler Recorder zur Langzeithustenmessung. Pneumologie 1996; 51: 555-559. 